\title{
An SDF-1a Gene-activated Collagen Scaffold Restores Pro-angiogenic Wound Healing Features in Human Diabetic Adipose-derived Stem Cells
}

\section{Ashang Luwang Laiva}

Tissue Engineering Research Group, Dept. of Anatomy and Regenerative Medicine, Royal College of Surgeons in Ireland, 123 St. Stephen's Green, Dublin 2, Ireland https://orcid.org/0000-0003-3810-8044 Fergal J. O'Brien

Tissue Engineering Research Group, Dept. of Anatomy and Regenerative Medicine, Royal College of Surgeons in Ireland, 123 St. Stephen's Green, Dublin 2, Ireland

Michael B. Keogh ( $\nabla$ mkeogh@rcsi-mub.com )

Tissue Engineering Research Group, Dept. of Anatomy and Regenerative Medicine, Royal College of Surgeons in Ireland, 123 St. Stephen's Green, Dublin 2, Ireland

\section{Research}

Keywords: Gene-activated scaffold, SDF-1a, human diabetic ADSCs, Angiogenesis, Wound healing

Posted Date: August 5th, 2020

DOl: https://doi.org/10.21203/rs.3.rs-52309/v1

License: (1) (i) This work is licensed under a Creative Commons Attribution 4.0 International License. Read Full License

Version of Record: A version of this preprint was published at Biomedicines on February 6th, 2021. See the published version at https://doi.org/10.3390/biomedicines 9020160 . 


\section{Abstract}

Background: Diabetic foot ulcer is one of the leading causes of leg amputation and mortality in diabetic patients. Autologous stem cell therapy holds some potential to be a solution to this problem, however diabetic stem cells are relatively dysfunctional and restrictive in their wound healing abilities. This study sought to explore if a novel collagen-chondroitin sulfate (coll-CS) scaffold functionalized with polyplex nanoparticles carrying the gene encoding for stromal-derived factor-1 alpha (SDF-1 a gene-activated scaffold) can enhance the regenerative functionality of human diabetic adipose-derived stem cells (ADSCs).

Methods: Gene-activated scaffolds were first prepared by soak-loading polyethyleneimine nanoparticles carrying the plasmid encoding for SDF-1a gene into a freeze-dried coll-CS scaffold. ADSCs from healthy and diabetic donors were then seeded on the gene-activated scaffold. The response of the ADSCs in the gene-activated scaffold was then compared against those of the healthy ADSCs cultured on the gene-free scaffold over 2 weeks period. Functional response in the ADSCs such as the activation of SDF-1a mediated signaling, production of bioactive factors, pro-angiogenic bioactivity of secreted factors, matrix deposition and remodeling was determined using proteome profiling, Matrigel assay, qRT-PCR and immunofluorescence.

Results: Overall, we found that SDF-1a gene-activated scaffold could restore pro-angiogenic regenerative response in the human diabetic ADSCs similar to the healthy ADSCs on the gene-free scaffold. Gene and protein expression analysis revealed that the SDF-1a gene-activated scaffold induced the overexpression of SDF-1a in diabetic ADSCs and engaged the receptor CXCR7, causing downstream signaling of $\beta$ arrestin as effectively as the transfected healthy ADSCs. The transfected diabetic ADSCs also effectively stimulated angiogenesis in endothelial cells while undergoing matrix remodeling characterized by reduction in deposition of fibronectin matrix and increase in the expression of basement membrane protein collagen IV. The SDF-1 a gene-activated scaffold also induced a controlled pro- healing response in the healthy ADSCs by disabling the signaling of early developmental factors while promoting the expression of tissue remodeling components.

Conclusion: We show that the SDF-1a gene-activated scaffold can overcome the deficiencies associated with diabetic ADSCs paving the way for autologous patient stem cell therapies in combination with novel biomaterials to treat diabetic foot ulcers.

\section{Introduction}

Stem cell driven wound healing is an inherent biological process that occurs to restore a damaged tissue [1]. The stem cells are recruited in response to signals released from the wound site such as the stromalderived factor-1 alpha (SDF-1a) and colony stimulating factor (CSF) [2,3]. However, in patients with underlying medical conditions such as diabetes, stem cells recruitment to the wound site is either delayed or reduced, contributing to progression of the wound to a more deleterious chronic state $[4,5]$. In diabetic 
foot ulcer patients, poor prognosis pose a serious risk for amputation, quality of life and mortality of the patient [6].

Rapid healing is considered the key to prevent amputation in DFU patients [7]. Emerging evidences suggest that the application of tissue-engineered grafts significantly outperform the standard-of-care (i.e. debridement and infection control with regular dressing changes) in the ability to accelerate healing [8]. Apligraf $^{\circledR}$ and Dermagraft ${ }^{\circledR}$ are two of the widely used FDA approved bioengineered constructs for diabetic foot ulcers [9]. Apligraf comprises of a dermal layer of human neonatal fibroblasts in a bovine type 1 collagen matrix and an epidermal layer formed by human neonatal keratinocytes [10]. However, owing to the multifunctional attributes of stem cells, ongoing studies on cell therapy for wound healing are being progressively conducted using stem cells [11]. Allogenic stem cells derived from the bone marrow [12], adipose tissue [13] and umbilical cord [14] have been investigated in clinical trials for DFU treatment.

One potential reason for using allogenic stem cells is the impaired functionality of the autologous diabetic stem cells [15-18]. Therapeutic gene-delivery to diabetic stem cells is one of the approaches that might potentially improve the functionality of diabetic stem cells [19]. Our previous studies have found that combining the therapeutic genes with 3D collagen scaffolds is an effective approach to enhance the functionality of stem cells. The scaffold acts a platform for supporting the 3-dimensional growth of the cells while also facilitating their transfection $[20,21]$. In our lab, we rely on the use of non-viral based vectors such as the polyethyleneimine (PEI) for transfection of the cells. The PEI possesses high transfection efficiency over a range of cell types and can easily condense in the presence of plasmid DNA to form highly stable nanoparticles [22,23]. These nanoparticles can then be soak-loaded onto the collagen scaffolds to generate the bioactive scaffold, also refered to as the gene-activated scaffold (GAS).

Stem cells from the bone marow are often the cell candidates while developing gene-activated scaffold based therapeutic modalities [24-26]. However, diabetic patients suffer from reduced stem cell populations in the bone marrow [27], suggesting that the BM-MSCs may not be ideal for developing personalised tissue-engineered products for diabetic patients [28]. Alternatively, the adipose tissue represents a more desirable source for harvesting autologous stem cells. The yield capacity of stem cells from the adipose tissue could be as high as 500 times that of the stem cells derived from the same mass of bone marrow [29]. Moreover, the stem cells from the adipose tissue could be harvested using a minimally invasive liposuction process [29].

Biomaterial scaffolds developed from copolymer of type 1 collagen and chondroitin sulfate (coll-CS) is one of the most clinically efficacious scaffolds used for wound healing [30]; for example, Integra's dermal regeneration template, which also received the FDA approval for use in DFU treatment [31]. In our previous study, we found that the coll-CS functionalised with nanoparticles carrying the pro-angiogenic gene SDF-1 a (SDF-1 a gene-activated scaffold) can significantly enhance the pro-angiogenic response in BM-MSCs [24]. The SDF-1 a primarily functions as a chemokine to recruit endothelial progenitors at the 
wound site to promote angiogenesis [32]. However, it is deficient in diabetic wounds [32] and is known to localize predominantly at the wound margins [33]. Therefore, we sought to investigate if the SDF-1a geneactivated scaffold could be used to restore the regenerative potential of human diabetic ADSCs and engineer a functionally enhanced graft for wound healing. Having initially established that the diabetic stem cells are functionally impaired [15-18], we investigated the functional improvement in the diabetic ADSCs with reference to healthy ADSCs cultured on the gene-free coll-CS scaffold. The functional improvement was determined based on the production of an array of angiogenic/anti-angiogenic factors, angiogenic bioactivity of the secreted factors and the expression patterns of extracellular matrix genes and proteins essential for wound healing.

\section{Materials And Methods}

\subsection{Preparation of polyplex}

Plasmid DNA (pDNA) encoding for the therapeutic gene SDF-1a (pSDF-1a) was obtained from InvivoGen, San Diego, USA. The plasmids were first amplified by transforming chemically competent DH5a E. coli cells (Biosciences, Ireland) according to the manufacturer's protocol. Transformed cells were then expanded in Lysogeny broth (LB) plates containing $100 \mu \mathrm{g} / \mathrm{mL}$ of blasticidin as the selective antibiotic for pSDF-1a. After $24 \mathrm{~h}$ at $37^{\circ} \mathrm{C}$, bacterial colonies were harvested and amplified in LB broth containing the appropriate antibiotic and cultured overnight in a shaker incubator at $37^{\circ} \mathrm{C}$. Plasmid purification was performed using a QIAGEN® EndoFree®Plasmid Maxi kit (Qiagen, Sussex, United Kingdom) and final nucleic acid concentration was determined using NanoDrop 1000 spectroscopy. Plasmids were further diluted in TE buffer to obtain a working concentration of $0.5 \mu \mathrm{g} / \mu \mathrm{l}$ and stored at $-20^{\circ} \mathrm{C}$ until use. Plasmid DNA (pDNA) encoding a non-therapeutic Gaussia Luciferase (pLuc) purchased from New England Biolabs, Massachusetts, USA was similarly amplified using ampicillin as the selective antibiotic. Based on our previous study, polyplex particles were formulated by initially mixing a specified amount of branched cationic $25 \mathrm{kDa}$ PEI (Sigma-Aldrich, Ireland) and anionic pDNA (fixed at a dose of $2 \mu \mathrm{g}$ ) to give an N/P ratio of 10.

\subsection{Cell expansion}

Human ADSCs (healthy, female, age 33; diabetic type 2, female, age 45) purchased from iXCells Biotechnologies, were expanded to passage 4 in ADSCs growth medium (Cat no. MD0003) supplied by the company.

\subsection{Cell seeding on SDF-1a gene-activated scaffold}

Solid porous coll-CS scaffolds were first developed by freeze-drying a blend solution of collagen type 1 and chondroitin sulfate, using the optimized protocol developed in our lab [34,35]. The scaffolds were then dehydrothermally (DHT) treated under vacuum at $105^{\circ} \mathrm{C}$ and further crosslinked using $14 \mathrm{mMN}-(3-$ Dimethylaminopropyl)-N'-ethylcarbodiimide hydrochloride and $5.5 \mathrm{mM} \mathrm{N}$-Hydroxysuccinimide (EDAC/NHS) (Sigma, UK) to mechanically reinforce the scaffolds. Using these gene-free coll-CS 
scaffolds, a preliminary test group was created by culturing healthy or diabetic ADSCs. Briefly, the scaffolds were hydrated in PBS and placed in a 12-well plate. The ADSCs at a total density of $5 \times 10^{5}$ cells $\left(2.5 \times 10^{5}\right.$ per side) were then seeded onto the scaffolds. After letting the cells settle for about 20 min, $2 \mathrm{ml}$ of OptiMEM (transfection media) was added, and the cellularized scaffolds were incubated at $37^{\circ} \mathrm{C}$ for $24 \mathrm{~h}$. For the final test group, a SDF-1a gene-activated scaffold was developed, which involves soak-loading the PEI-pSDF-1a polyplex nanoparticles into the freeze-dried scaffolds. Healthy/diabetic ADSCs at the same cell density as on gene-free scaffold was seeded and incubated in OptiMEM. In this experimental run, healthy ADSCs on the gene-free scaffold were used as control. After incubation in OptiMEM for $24 \mathrm{~h}$, the cellularized gene-free or gene-activated scaffolds were transferred into new 12-well plates, and fed with $2 \mathrm{ml}$ of ADSCs growth medium. Media change was then performed every 3-4 days until day 14 by collecting $1 \mathrm{ml}$ of the conditioned media (CM) and replacing it with new media. All CM were stored at $-80^{\circ} \mathrm{C}$ until analysis.

\subsection{Proteome profiling of secreted factors from healthy and diabetic ADSCs on the gene-free scaffold}

In order to first confirm functional impairment in diabetic ADSCs, secreted factors produced by the diabetic ADSCs was compared against those produced by healthy ADSCs, using an angiogenesis

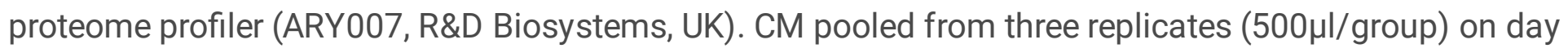
7 , was used for the analysis. The amount of secreted factors was semi-quantitatively determined from the mean volume intensities obtained using ChemiDoc XRS+ (Biorad). The high sensitivity mode of the ChemiDoc XRS+ was used to detect the bound analytes on the array.

\section{5 qRT-PCR analysis to determine functional gene expression in ADSCs on SDF-1a gene-activated scaffold}

In order to determine the activation of functional genes, the ADSCs from the scaffolds or SDF-1a GAS were harvested on the 7th and 14th day for analysis. The cells were first lysed using Qiazol reagent (Qiagen, UK) to extract the RNA. Chloroform was then added to separate the cell lysate into protein, DNA, and RNA phases. RNA was extracted using the RNeasy Kit (Qiagen, UK). The RNA quality and quantity were determined using a Multiskan Go plate reader (Thermo Scientific, UK) with the absorbance set at $260 \mathrm{~nm}$. Prior to using a reverse transcriptase enzyme (Qiagen, UK) for CDNA synthesis, genomic DNA was removed by heating the RNA to $42^{\circ} \mathrm{C}$ for 2 min using a genomic DNA wipeout buffer (Qiagen, UK). qRT-PCR was then performed on cDNA using the primers -Hs_CXCL12_1_SG, Hs_CXCR4_1_SG, Hs_ACKR3_1_SG, Hs_ARRB_1_SG, Hs_FN1_1_SG and Hs_COL4A1_1_SG, which encodes for SDF-1a, CXCR4, CXCR7, $\beta$-Arrestin, Fibronectin, and Collagen IV respectively. Fold change in mRNA expression

relative to the respective controls at day 7 and 14 was calculated using the $2^{-\Delta \Delta C T}$ method from averages of three samples for each group. Human GAPDH (Hs_GAPDH_1_SG) was used as the housekeeping gene.

\subsection{Proteome profiling of secreted factors from healthy and diabetic ADSCs on SDF-1a gene-activated scaffold}


To understand how the SDF-1a gene-activated scaffold affected the production of therapeutic factors in diabetic ADSCs, we adopted the similar profiling method described in section 2.4. The secretory profile of the diabetic ADSCs was again compared to that of the healthy ADSCs on the gene-free scaffold and on the gene-activated scaffold.

\subsubsection{Pro-angiogenic bioactivity analyses of secreted factors from the ADSCs on SDF-1a gene-activated scaffold}

Next, to determine the angiogenic impact of secreted factors, HUVECs were exposed to CM collected from the ADSCs' culture on day 7, and the subsequent angiogenic response by HUVECs in terms of network branching and tubule formation on Matrigel ${ }^{\mathrm{TM}}$ was assessed. The HUVECs were seeded at a density of 3 $\times 10^{4}$ cells/well of a 48 -well plate pre-coated with $120 \mu$ l of Matrigel for $30 \mathrm{~min}$ at $37^{\circ} \mathrm{C}$. The angiogenic response was monitored at 4,8 , and 24 h post-exposure to $C M$. At $8 \mathrm{~h}$, the mean number of branching points and tubules were counted using the ImageJ software (ImageJ, NIH, Maryland, USA).

\subsection{Immunofluorescent imaging}

Immunofluorescence staining was performed to detect the expression of target proteins by ADSCs. Scaffolds harvested at days 7 and 14 were used for the study. The scaffolds were first washed with PBS and fixed in 10\% neutral buffered formalin for $20 \mathrm{~min}$. The fixed samples were then processed using the standard protocol for paraffinization. The blocks were then cut into 8- $\mu \mathrm{m}$ thick slices and collected on charged slides. The sections were then deparaffinized using xylene followed by rehydration of the section with decreasing gradients of ethanol. Subsequently, the cells were permeabilized with $0.2 \%$ Tween ${ }^{\circledR} 20$ (Sigma-Aldrich, France) solution in PBS for 30 min (10 min wash $\times 3$ ) and blocked using 10\% NGS (Normal Goat Serum, Invitrogen, UK)/5\% BSA/0.3M Glycine (prepared in permeabilizing solution) for $1 \mathrm{~h}$. The slides were briefly rinsed in PBS and then incubated at $4^{\circ} \mathrm{C}$ overnight with antibodies to SDF-1a (rabbit mAb, 1:100, ab155090), CXCR7 (mouse mAb, 1:50, MAB42273), Fibronectin (rabbit polyAb, 1:100, ab2413) and Collagen IV (rabbit polyAb, 1:100, ab6586) All the primary antibodies were obtained from Abcam UK, except CXCR7 (R\&D systems, UK).

The next day, the slides were rinsed in PBS thrice for 2-3 min each to remove any unbound primary antibodies. Subsequently, the slides were incubated in either Alexa 488-conjugated goat anti-mouse IgG (A32723, Invitrogen, UK) or Alexa 594-conjugated goat anti-rabbit IgG (A11012, Invitrogen, UK) at 1:800 dilution at room temperature for $1 \mathrm{~h}$ in the dark. The rinsing step was performed as before and counterstained for nuclei using the mounting medium with DAPI (ab104139, Abcam, UK). The slides were then imaged using fluorescence microscope (Olympus BX43, Japan) at 40x objective. Samples incubated

with only secondary antibodies were used as controls. All the antibodies were diluted in 1\% BSA in PBS. 


\subsubsection{Image analysis}

The "ImageJ" software (ImageJ, NIH, Maryland, USA) was used to semi-quantitatively determine the amount of expressed proteins. For each marker, a constant threshold value was first determined through preliminary imaging of various sections. Using the set threshold value, integrated density (stained area $x$ mean gray value) of the images was determined and then normalized to the number of cells (DAPI counting) to give a final mean fluorescence density per cell. An average was quantified from 8-12 random images per sample, with a minimum of 3 samples per group. The averages obtained from the 3 samples/group was then used for measuring relative expression between the groups.

\subsection{Statistical analysis}

All results are expressed as mean \pm standard deviation. Unpaired, two-tailed, t-test was used to demonstrate the statistical significance between groups, where $p<0.05$ was considered to be significant.

\section{Results}

\subsection{Diabetes impairs signaling of functional factors in human ADSCs}

The soluble factors produced by the ADSCs on the gene-free scaffold at day 7 was anlaysed. The soluble factors were broadly grouped into metabolic regulators (Fig. 1A), clotting factors (Fig. 1B), inflammatory cytokines (Fig. 1C), angiogenic factors (Fig. 1D), vascular homeostatic factors (Fig. 1E) and antiangiogenic factors (Fig. 1F). As anticipated, diabetic ADSCs demonstrated an impaired regulation of the signaling factors. Compared to the healthy ADSCs, the diabetic ADSCs produced a 2-fold higher amount of the insulin-like growth factor-binding protein 3 (IGFBP-3), an inhibitor of insulin-mediated glucose metabolism [36]. This response confirms the impaired metabolic state of the diabetic ADSCs.

Furthermore, healthy ADSCs showed a highly balanced production of inflammatory cytokines interleukin8 (IL-8 - a chemoattractant for neutrophils) and monocyte chemoattractant protein (MCP-1), while diabetic ADSCs failed to demonstrate this effect. The diabetic ADSCs also displayed a 2-fold higher production of angiogenesis inhibitors - plasminogen activator inhibitor (PAl-1, also a clotting factor [37]), tissue inhibitor of metalloproteinase (TIMP-1) [38], thrombospondin (TSP-1) [39], and pigment epitheliumderived factor (PEDF) [40]. This anti-angiogenic response was further accompanied by a 2-fold higher production of vascular destabilizing factor angiopoietin-2 (Ang-2) [41]. We noted these differences despite their ability to comparably produce the pro-angiogenic factors (VEGF and angiogenin) as that of the healthy ADSCs. Therefore, taken together, this finding verifies that functional signaling is impaired in the diabetic ADSCs used in this study.

\subsection{SDF-1a gene-activated scaffold promotes overexpression of SDF-1a mRNA and engages the CXCR7/ $\beta$-Arrestin signaling in diabetic ADSCs}


Gene expression analysis first showed that the SDF-1 a gene-activated scaffold caused the overexpression of SDF-1 a mRNA in diabetic ADSCs similar to the transfected healthy ADSCs. Having observed this, we then looked for the receptors associated with SDF-1a signaling. Of the two primary receptors for SDF-1a - CXCR4 and CXCR7, we could only detect the expression of CXCR7 mRNA. The healthy ADSCs on the gene-activated scaffold demonstrated significantly $(p<0.01)$ higher $(63 \%)$ expression of CXCR7 mRNA than its gene-free scaffold equivalent. However, the diabetic ADSCs despite overexpressing the SDF-1 a mRNA showed a significantly $(p<0.005)$ lower $(70 \%)$ activation of CXCR7 mRNA than the healthy ADSCs on the gene-free scaffold.

Immunofluorescence imaging then showed that all the ADSCs abundantly expressed SDF-1a proteins however, contrary to the gene-expression data, no obvious differences in the expression was observed. The diabetic ADSCs on the gene-activated scaffold showed the highest SDF-1a expression while the expression of CXCR7 was comparable to that of the healthy ADSCs on the gene-free scaffold. The transfected healthy ADSCs on the contrary, showed a significantly lower $(p<0.001 ; 61 \%)$ expression of CXCR7 than its gene-free scaffold equivalent.

Next, we assessed the activation of $\beta$-arrestin, which is the major downstream signal transducer of the SDF-1 $a / C X C R 7$ axis [42]. We found that the overexpression of SDF-1a in both healthy and diabetic ADSCs enhanced the expression of $\beta$-arrestin mRNA (1.91 \pm 0.33 for healthy; $1.88 \pm 0.5$ for diabetic) by $\sim 2$-fold $(p<0.05)$ than that of the healthy ADSCs on the gene-free scaffold.

\subsection{SDF-1a gene-activated scaffold restores a healthy-like signaling of functional factors in diabetic ADSCs}

Having determined that the SDF-1a gene-activated scaffold could effectively engage the SDF-1a/CXCR7 axis in the diabetic ADSCs, we then measured the levels of functional factors produced by the diabetic ADSCs. The diabetic ADSCs on the gene-activated scaffold demonstrated a very similar pattern of production of the angiogenic/anti-angiogenic factors as that of the healthy ADSCs on the gene-free scaffold (Fig. 3). However, the transfected diabetic ADSCs did not downregulate the production of its inflammatory cytokine IL-8. It rather enhanced the production of MCP-1 to a level comparable to IL-8. On the other hand, the healthy ADSCs on the gene-activated scaffold showed an immense reduction in the production of MCP-1 and VEGF. The transfected healthy ADSCs also showed a moderate shift in the pattern of production of anti-angiogenic factors (Fig. 3E). For instance, the production of TIMP-1 increased by $51 \%$ while the production of TSP- 1 decreased by $31 \%$ relative to that produced by its genefree scaffold equivalent.

\subsubsection{Diabetic ADSCs on the SDF-1a gene-activated scaffold effectively enhances angiogenesis in endothelial cells}

One of the significant challenges in the healing of diabetic wounds is the lack of angiogenesis [43]. Therefore, having noted an active pro-angiogenic profile in the transfected diabetic ADSCs, we assessed the pro-angiogenic bioactivity of the secreted factors on endothelial cells. Treatment of the endothelial 
cells with CM from the transfected diabetic ADSCs promoted the formation of well-defined endothelial tubular networks by $8 \mathrm{~h}$ post-treatment. The mean number of branching points and tubules was $43 \pm 8$ and $62 \pm 8$, respectively. The angiogenic response was relatively milder (39 \pm 9 branching points; $56 \pm 6$ tubules) when stimulated with CM from healthy ADSCs on the gene-free scaffold. The angiogenic response was further lower ( $20 \pm 3$ branching points; $32 \pm 9$ tubules) in the endothelial groups exposed to $\mathrm{CM}$ from the transfected healthy ADSCs. Comparatively, the diabetic ADSCs on the SDF-1a geneactivated scaffold demonstrated significantly $(p<0.05)$ superior pro-angiogenic potency than its healthy counterpart.

\subsection{SDF-1a gene-activated scaffold promotes pro-wound healing matrix remodeling response in diabetic ADSCs}

Fibronectin is one of the first matrix proteins produced during the early stages of cellular development. It also acts as a provisional scaffold for subsequent matrix deposition [44]. Therefore, we first assessed the expression of fibronectin gene and deposition of its matrix. On day 7, the diabetic ADSCs on the geneactivated scaffold showed a significantly enhanced transcription of the FN1 gene than the healthy ADSCs on the gene-free scaffold (Fig. 5). Immunofluorescence anlaysis of matrix deposition further showed that the diabetic ADSCs abundantly deposited the matrix similar to that of the healthy ADSCs on the gene-free scaffold (Fig. 6) However, on day 14, the fibronectin matrix remodeled into thin continuous fibers, causing an overall reduction in the spatial coverage by $40 \%$ than that of the healthy ADSCs on the gene-free scaffold. Conversely, the healthy ADSCs on the gene-activated scaffold did not show the activation of the FN1 gene on day 7 , but moderately downregulated its expression by $45 \%$ than its genefree scaffold equivalent on day 14 . At both time points, fibronectin deposition by the healthy ADSCs on the gene-activated scaffold was significanlty $(p<0.05)$ lower than its gene-free scaffold equivalent (Fig. $6 \mathrm{~B})$.

We next assessed the expression of collagen IV, which is essential for the formation of the basement membrane [45], a specialized structure that binds dermis to the epidermis. Conversely to FN1 gene expression, we noted a significant $(p<0.01$ ) early activation (day 7$)$ of the COL4A1 gene only in the healthy ADSCs on the gene-activated scaffold. Furthermore, matrix deposition also increased significantly in the healthy ADSCs on the gene-activated scaffold than its gene-free scaffold equivalent. Meanwhile, the diabetic ADSCs on the gene-activated scaffold showed a temporal increase in the expression of COL4A1 gene. On day 14 , the expression of COL4A1 gene by the diabetic ADSCs significantly $(p<0.005)$ exceeded that of the healthy ADSCs on the gene-free scaffold. However, at the protein level, the diabetic ADSCs on the gene-activated scaffold deposited comparable amounts of the collagen IV matrix as that of the healthy ADSCs on the gene-free scaffold.

Taking the results together, we show that the SDF-1a gene-activated scaffold restores the pro-regenerative capacity in diabetic ADSCs similar to the healthy ADSCs on the gene-free scaffold. Further, we show that the SDF-1 a gene-activated scaffold also promotes controlled development of healthy ADSCs towards a pro-healing nature. Fig. 7 depicts the overall findings of this study. 


\section{Discussion}

In this study, we explored the therapeutic impact of an SDF-1a gene-activated collagen scaffold on human diabetic ADSCs as an approach to develop a functional 3D autologous graft for diabetic wound healing. Transfection of the SDF-1a in the diabetic ADSCs using the gene-activated scaffold led to restoration of the pro-angiogenic signaling behavior of the diabetic ADSCs similar to the healthy ADSCs on the gene-free scaffold. The transfected diabetic ADSCs also exhibited active matrix remodeling events characterized by a reduction in fibronectin expression and increase in the deposition of basement membrane protein collagen IV. Meanwhile, in healthy ADSCs, the SDF-1a gene-activated scaffold promoted controlled cellular maturation, by instructing the ADSCs to disable the sigaling of early developmental factors and promote the production of tissue remodeling components.

An impaired healing response is a common occurrence in diabetic patients, and one reason is the reduced functionality of cells to mediate the regenerative process [32]. Mainly, in diabetic ADSCs, a significant factor limiting its application for cellular therapy is its low angiogenic potency $[15,18,46,47]$. Nevertheless, wound healing is a complex process controlled by a cocktail of signaling factors [48,49]. Therefore, we used an angiogenesis proteome profiler that enabled us to differentiate between the multiple signaling factors produced by the healthy and diabetic ADSCs when grown in a 3D scaffold. We noted that it is not necessarily the lack of a pro-angiogenic component but an impaired production of anti-angiogenic and vascular destabilizing factors that may also limit the functional potency of the ADSCs. By delivering the pro-angiogenic SDF-1a gene using a gene-activated scaffold, we show that the impaired signaling in the diabetic ADSCs could be restored to a healthy-like state. Similar response has also been achieved in diabetic mice ADSCs lentivirally transduced with glyoxalase-1 gene [19]. As the soluble factors are essential for instructing surrounding cells such as the endothelial cells and modulation of the wound environment [50], the healthy-like behaviour of the diabetic ADSCs may contribute to accelerated healing. The enhanced pro-angiogenic bioactivity of the secreted factors as shown in fig. 4 proves that the diabetic ADSCs on the gene-activated scaffold could functionally activate surrounding cells. In tissue engineering strategies, the ability of a construct to induce enhanced angiogenic response is crucial for faster integration of the graft with the host environment [51].

Among the secreted factors, a notable response induced by the gene-activated scaffold in thediabetic ADSCs is the elevated production of MCP-1. In diabetic wounds, the lack of MCP-1 is considered a major factor halting the progression of healing [52,53]. Wood et al. showed that early treatment with MCP-1 at the time of injury significantly enhanced macrophage infiltration, thereby accelerating healing in diabetic mice [52]. Investigations on healthy wounds also found that the elevation of MCP- 1 sequential to IL-8 is crucial to drive an acute-like healing [54]. Therefore, despite the production of high levels of IL-8, the ability of the transfected diabetic ADSCs to equilibrate the level of MCP-1 to IL-8 may facilitate timely transition to the subsequent healing phase.

While the SDF-1 a gene-activated scaffold works to improve the angiogenic homeostasis in diabetic ADSCs, it appears to disable the signaling components of the early healing phase in healthy ADSCs. For 
instance, in healthy ADSCs, the SDF-1a gene-activated scaffold robustly dampened the production of proinflamatory MCP-1 and pro-angiogenic VEGF [55]. However, itdid not compromise the signaling of the anti-angiogenic tissue inhibitors, which are essential for tissue remodeling [37-40]. It has been observed that the stem cells possess a unique ability to sense external stimuli and accordingly modulate their secretome to offer a cytoprotective effect [56]. In our study, the modulatory impact of SDF-1a geneactivated scaffold in the ADSCs appears to be controlled by the receptor CXCR7 (Fig. 2C). A recent study that investigated the impact of SDF-1a on the differentiation potential of embryonic stem cells (ESCs) showed that the presence of active or inactive CXCR7 differentially modulates the development of ESCs [57]. The group showed that the engagement of active CXCR7 by SDF-1 a leads to downregulation of pluripotency markers without affecting the expression of factors essential for development in wild-type ESCs [57]. While in mutant cells with inactive CXCR7, the expression of the pluripotency markers was barely affected [57]. Similarly, given that the diabetic ADSCs are relatively dysfunctional, the sensitivity of its CXCR7 to the overexpressed SDF-1a is probably weaker, leading to a varied response than the transfected healthy ADSCs. Nevertheless, activation of CXCR7 is fundamentally known to promote survival and proliferation of stem cells [14].

Since CXCR4 is the classical receptor of SDF-1a [14,58], we anticipated that the overexpression of SDF-1a by the transfected ADSCs in the gene-activated scaffold would upregulate the expression of CXCR4. However, we barely detected the expression of CXCR4 mRNAs even in the untransfected healthy ADSCs. Similar case has been observed in MSCs [59] but we cannot rule out that the gene is completely degraded, as it would lead to cell death [60]. It has been observed that the CXCR4 gene is generally expressed at very low levels in human ADSCs and is also the least expressed among the set of chemokine receptor genes [61]. Another factor for the undetection of CXCR4 could be the activation of CXCR7. The activation of CXCR7 can dampen the expression of CXCR4 [62]. It is unclear how the CXCR7 gene is induced in the ADSCs in the gene-free scaffold however; a study by Lisignoli et al. suggests that the matrix may modulate the expression of chemokine receptors. They found that the transcriptional expression of SDF-1 $a$ and CXCR4 is reversed when the MSCs are cultured on a hyaluronic acid-based scaffold than on a plastic substrate [63]. The MSCs on the hyaluronic acid scaffold showed downregulation of SDF-1a mRNA while upregulating CXCR4 mRNA relative to the MSCs on the plastic substrate [63]. The group found that the activation of CD54, a cell surface receptor of hyaluronan on the MSCs modulated this response [63]. In our context, the ADSCs are known to express the collagen receptor a2 $\beta 1$ integrin [64]. The a2 $\beta 1$ integrin promotes the adhesion and proliferation of stem cells on collagen [65]. Additionally, CXCR7 is essential for the promotion of proliferation and survivability in ADSCs $[14,66,67]$. Therefore, assuming the regulatory role of matrix, it appears that a proliferative mechanism may have been activated upon initial adhesion leading to the upregulation of CXCR7 but CXCR4.

The adipose ECM is also known to possess pro-healing properties[68]. Therefore, we investigated how the SDF-1 a gene-activated scaffold affects diabetic ADSCs in terms of matrix deposition and remodeling. As such, the expression and deposition pattern of a provisional matrix protein, fibronectin and a relatively mature basement membrane protein collagen IV was analyzed. The fibronectin is not only essential for supporting the adhesion and migration of cells but also provide a scaffold for subsequent collagen 
deposition [44]. However, diabetic skin lacks this feature and is one of the causes that impede healing $[69,70]$. To improve healing, soluble forms of fibronectin are supplemented to the wound to facilitate the assembly of the fibronectin matrix and promote healing $[71,72]$. Here, we show that the SDF-1a geneactivated scaffold can effectively enhance the deposition of the fibronectin matrix by the diabetic ADSCs, imparting the potential to drive healing. Furthermore, the response that the transfected diabetic ADSCs is driven towards healing could also be evident from its high transcriptional activity of COL4A1 gene and assembly of the collagen IV matrix over time. The SDF-1a gene-activated scaffold also enhanced the deposition of collagen IV in the healthy ADSCs suggesting that it promotes cellular maturation. However, the increase in collagen IV deposition by the transfected healthy ADSCs occurred despite bypassing the activation of either the FN1 gene or its assembly as a matrix. Taken together, these events suggest that the SDF-1 a gene-activated scaffold promotes controlled remodeling of ADSCs' ECM to create a prohealing environment regardless of the physiological state of the ADSCs. This controlled response in the ADSCs could be attributed to the homeostatic role of SDF-1a [73].

\section{Conclusion}

In this study, we report that a 3D collagen-chondroitin sulfate scaffold functionalized with a proangiogenic SDF-1 a gene could be used to enhance the functionality of human diabetic ADSCs as effective as the healthy ADSCs on the gene-free scaffold. Specifically, overexpression of SDF-1a in the diabetic ADSCs led to normalization of the production of the therapeutic factors, restoring its proangiogenic potency. The diabetic ADSCs also exhibited a pro-healing feature characterized by activematrix remodeling of fibronectin and collagen IV matrix. We also note that, it is not necessarily the lack of a pro-angiogenic component but an impaired production of anti-angiogenic and vascular destabilizing factors that may also limit the functional potency of diabetic ADSCs. Conclusively, we have shown that a pro-angiogenic collagen biomaterial can enhance the wound healing response of typically dysfunctional dADSCs, paving the way for better treatment of patient-specific DFU treatment.

\section{Declarations}

Ethical approval and consent to participate: Not Applicable

Consent for publication: Not Applicable

Availability of data and materials: The datasets during and/or analysed during the current study available from the corresponding author on reasonable request.

Competing interests: The authors declare that they have no competing interests.

Authors' contributions: ALL planned the experiment, performed the experiments, analysed/interpreted the data and written the manuscript. FOB and MBK reviewed the data and the manuscript. All authors read and approved the final manuscript. 
Funding: This work was funded by RCSI Dilmun PhD scholarship

Acknowledgements: Not Applicable

\section{References}

1. Wang $Y$, Sun $Y$, Yang $X Y$, et al. Mobilised bone marrow-derived cells accelerate wound healing. Int Wound J. 2013;10: 473-479.

2. Petit I, Szyper-Kravitz M, Nagler A, et al. G-CSF induces stem cell mobilization by decreasing bone marrow SDF-1 and up-regulating CXCR4. Nat Immunol. 2002;3: 687-694.

3. Nassar D, Batteux F, Raymond K, et al. Delayed healing of sickle cell ulcers is due to impaired angiogenesis and CXCL12 secretion in skin wounds. J Invest Dermatol. 2016;136: 497-506.

4. Laiva AL, O'Brien FJ and Keogh MB. Innovations in gene and growth factor delivery systems for diabetic wound healing. J Tissue Eng Regen Med. 2018;12: e296-e312.

5. Dinh T, Tecilazich F, Kafanas A, et al. Mechanisms involved in the development and healing of diabetic foot ulceration. Diabetes. 2012;61: 2937-2947.

6. Hunt DL. Diabetes: foot ulcers and amputations. BMJ Clin Evidence. 2011;2011:

7. Zelen CM, Orgill DP, Serena T, et al. A prospective, randomised, controlled, multicentre clinical trial examining healing rates, safety and cost to closure of an acellular reticular allogenic human dermis versus standard of care in the treatment of chronic diabetic foot ulcers. Int Wound J. 2017;14: 307-315.

8. Jiang Y, Chen B, Liu Y, et al. Effect of collagen scaffold with adipose-derived stromal vascular fraction cells on diabetic wound healing: A study in a diabetic porcine model. Tissue Eng Regen Med. 2013;10: 192-199.

9. Hart CE, Loewen-Rodriguez A and Lessem J. Dermagraft: use in the treatment of chronic wounds. Adv Wound Care. 2012;1: 138-141.

10. Dinh TL and Veves A. The efficacy of Apligraf in the treatment of diabetic foot ulcers. Plast Reconst Surg. 2006;117: 152S-157S.

11. Lopes L, Setia O, Aurshina A, et al. Stem cell therapy for diabetic foot ulcers: a review of preclinical and clinical research. Stem Cell Res Ther. 2018;9: 188.

12. Lu D, Chen B, Liang Z, et al. Comparison of bone marrow mesenchymal stem cells with bone marrowderived mononuclear cells for treatment of diabetic critical limb ischemia and foot ulcer: a double-blind, randomized, controlled trial. Diabetes Res Clin Prac. 2011;92: 26-36. 
13. Lee HC, An SG, Lee HW, et al. Safety and effect of adipose tissue-derived stem cell implantation in patients with critical limb ischemia. Circulation J. 2012 1204091686-1204091686.

14. Li Q, Zhang A, Tao C, et al. The role of SDF-1-CXCR4/CXCR7 axis in biological behaviors of adipose tissue-derived mesenchymal stem cells in vitro. Biochem Biophys Res Commun. 2013;441: 675-680.

15. Kim SM, Kim YH, Jun YJ, et al. The effect of diabetes on the wound healing potential of adiposetissue derived stem cells. Int Wound J. 2016;13: 33-41.

16. Kim H, Han JW, Lee JY, et al. Diabetic mesenchymal stem cells are ineffective for improving limb ischemia due to their impaired angiogenic capability. Cell Transplant. 2015;24: 1571-1584.

17. Massee M, Chinn K, Lim JJ, et al. Type I and II diabetic adipose-derived stem cells respond in vitro to dehydrated human amnion/chorion membrane allograft treatment by increasing proliferation, migration, and altering cytokine secretion. Adv Wound Care. 2016;5: 43-54.

18. Cianfarani F, Toietta G, Di Rocco G, et al. Diabetes impairs adipose tissue-derived stem cell function and efficiency in promoting wound healing. Wound Repair Regen. 2013;21: 545-553.

19. Peng Z, Yang X, Qin J, et al. Glyoxalase-1 overexpression reverses defective proangiogenic function of diabetic adipose-derived stem cells in streptozotocin-induced diabetic mice model of critical limb ischemia. Stem Cells Trans Med. 2017;6: 261-271.

20. O'Brien FJ. Biomaterials \& scaffolds for tissue engineering. Mater Today. 2011;14: 88-95.

21. Wang $C, M a L$ and Gao C. Design of gene-activated matrix for the repair of skin and cartilage. Polym J. 2014;46: 476-482.

22. Lackington WA, Raftery RM and O'Brien FJ. In vitro efficacy of a gene-activated nerve guidance conduit incorporating non-viral PEI-pDNA nanoparticles carrying genes encoding for NGF, GDNF and cJun. Acta Biomater. 2018;75: 115-128.

23. Walsh DP, Raftery RM, Castaño IM, et al. Transfection of autologous host cells in vivo using gene activated collagen scaffolds incorporating star-polypeptides. J Control Release. 2019;304: 191-203.

24. Laiva AL, Raftery RM, Keogh MB, et al. Pro-angiogenic impact of SDF-1a gene-activated collagenbased scaffolds in stem cell driven angiogenesis. Int J Pharm. 2018;544: 372-379.

25. Raftery RM, Tierney EG, Curtin CM, et al. Development of a gene-activated scaffold platform for tissue engineering applications using chitosan-pDNA nanoparticles on collagen-based scaffolds. J Control Release. 2015;210: 84-94.

26. Kolakshyapati P, Li X, Chen C, et al. Gene-activated matrix/bone marrow-derived mesenchymal stem cells constructs regenerate sweat glands-like structure in vivo. Sci Rep. 2017;7: 1-13. 
27. Cassidy FC, Shortiss C, Murphy CG, et al. Impact of Type 2 Diabetes Mellitus on Human Bone Marrow Stromal Cell Number and Phenotypic Characteristics. Int J Mol Sci. 2020;21: 2476.

28. Nishiguchi MA, Spencer CA, Leung DH, et al. Aging suppresses skin-derived circulating SDF1 to promote full-thickness tissue regeneration. Cell Rep. 2018;24: 3383-3392. e5.

29. Holm JS, Toyserkani NM and Sorensen JA. Adipose-derived stem cells for treatment of chronic ulcers: current status. Stem Cell Res Ther. 2018;9: 142.

30. Lohana P, Hassan S and Watson S. Integra ${ }^{T M}$ in burns reconstruction: our experience and report of an unusual immunological reaction. Ann Burn Fire Disasters. 2014;27: 17.

31. Driver VR, Lavery LA, Reyzelman AM, et al. A clinical trial of Integra Template for diabetic foot ulcer treatment. Wound Repair Regen. 2015;23: 891-900.

32. Gallagher KA, Liu Z-J, Xiao M, et al. Diabetic impairments in NO-mediated endothelial progenitor cell mobilization and homing are reversed by hyperoxia and SDF-1a. J Clin Invest. 2007;117: 1249-1259.

33. Toksoy A, Müller V, Gillitzer R, et al. Biphasic expression of stromal cell-derived factor-1 during human wound healing. Brit J Dermatol. 2007;157: 1148-1154.

34. O'Brien FJ, Harley BA, Yannas IV, et al. Influence of freezing rate on pore structure in freeze-dried collagen-GAG scaffolds. Biomaterials 2004;25: 1077-1086.

35. Haugh MG, Murphy CM and O'Brien FJ. Novel freeze-drying methods to produce a range of collagenglycosaminoglycan scaffolds with tailored mean pore sizes. Tissue Eng Part C Methods. 2010;16: 887894.

36. Kim H-S. Role of insulin-like growth factor binding protein-3 in glucose and lipid metabolism. Ann Pediatr Endocrinol Metabol. 2013;18: 9.

37. Wu J, Strawn TL, Luo M, et al. Plasminogen activator inhibitor-1 inhibits angiogenic signaling by uncoupling vascular endothelial growth factor receptor-2-aV $\beta 3$ integrin cross talk. Arterioscler Thromb Vasc Biol. 2015;35: 111-120.

38. Akahane T, Akahane M, Shah A, et al. TIMP-1 inhibits microvascular endothelial cell migration by MMP-dependent and MMP-independent mechanisms. Exp Cell Res. 2004;301: 158-167.

39. Rohrs JA, Sulistio CD and Finley SD. Predictive model of thrombospondin-1 and vascular endothelial growth factor in breast tumor tissue. NPJ Syst Biol Appl. 2016;2: 16030.

40. Michalczyk ER, Chen L, Fine D, et al. Pigment Epithelium-Derived Factor (PEDF) as a Regulator of Wound Angiogenesis. Sci Rep. 2018;8: 11142. 
41. Benest AV, Kruse K, Savant S, et al. Angiopoietin-2 is critical for cytokine-induced vascular leakage. PLoS One. 2013;8: e70459.

42. Rajagopal S, Kim J, Ahn S, et al. $\beta$-arrestin-but not G protein-mediated signaling by the "decoy" receptor CXCR7. Proc Natl Acad Sci. 2010;107: 628-632.

43. Bitar MS. Diabetes Impairs Angiogenesis and Induces Endothelial Cell Senescence by Up-Regulating Thrombospondin-CD47-Dependent Signaling. Int J Mol Sci. 2019;20: 673.

44. Hsiao $\mathrm{C}-\mathrm{T}$, Cheng $\mathrm{H}-\mathrm{W}$, Huang $\mathrm{C}-\mathrm{M}$, et al. Fibronectin in cell adhesion and migration via Nglycosylation. Oncotarget 2017;8: 70653 .

45. Ramos-Lewis W, LaFever KS and Page-McCaw A. A scar-like lesion is apparent in basement membrane after wound repair in vivo. Matrix Biol. 2018;74: 101-120.

46. Rennert RC, Sorkin M, Januszyk M, et al. Diabetes impairs the angiogenic potential of adipose-derived stem cells by selectively depleting cellular subpopulations. Stem Cell Res Ther. 2014;5: 79.

47. Dzhoyashvili NA, Efımenko AY, Kochegura TN, et al. Disturbed angiogenic activity of adipose-derived stromal cells obtained from patients with coronary artery disease and diabetes mellitus type 2 . J Trans Med. 2014;12: 337.

48. Werner S and Grose R. Regulation of wound healing by growth factors and cytokines. Physiol Rev. 2003;83: 835-870.

49. Barrientos S, Stojadinovic O, Golinko MS, et al. Growth factors and cytokines in wound healing. Wound Repair Regen. 2008;16: 585-601.

50. Park S-R, Kim J-W, Jun H-S, et al. Stem cell secretome and its effect on cellular mechanisms relevant to wound healing. Mol Ther. 2018;26: 606-617.

51. Perry L, Landau S, Flugelman MY, et al. Genetically engineered human muscle transplant enhances murine host neovascularization and myogenesis. Commun Biol. 2018;1: 1-13.

52. Wood S, Jayaraman V, Huelsmann EJ, et al. Pro-inflammatory chemokine CCL2 (MCP-1) promotes healing in diabetic wounds by restoring the macrophage response. PloS One. 2014;9: e91574.

53. Galkowska H, Wojewodzka $U$ and Olszewski WL. Low recruitment of immune cells with increased expression of endothelial adhesion molecules in margins of the chronic diabetic foot ulcers. Wound Repair Regen. 2005;13: 248-254.

54. Engelhardt E, Toksoy A, Goebeler M, et al. Chemokines IL-8, GROa, MCP-1, IP-10, and Mig are sequentially and differentially expressed during phase-specific infiltration of leukocyte subsets in human wound healing. Am J Pathol. 1998;153: 1849-1860. 
55. Weinheimer-Haus EM, Judex S, Ennis WJ, et al. Low-intensity vibration improves angiogenesis and wound healing in diabetic mice. PloS One. 2014;9: e91355.

56. Ellison DD, Suhail Y, Afzal J, et al. Dynamic secretome of bone marrow-derived stromal cells reveals a cardioprotective biochemical cocktail. Proc Natl Acad Sci. 2019;116: 14374-14383.

57. Kowalski K, Brzoska E and Ciemerych MA. The role of CXC receptors signaling in early stages of mouse embryonic stem cell differentiation. Stem Cell Res. 2019;41: 101636.

58. Liu H, Liu S, Li Y, et al. The role of SDF-1-CXCR4/CXCR7 axis in the therapeutic effects of hypoxiapreconditioned mesenchymal stem cells for renal ischemia/reperfusion injury. PloS One. 2012;7: e34608.

59. Wynn RF, Hart CA, Corradi-Perini C, et al. A small proportion of mesenchymal stem cells strongly expresses functionally active CXCR4 receptor capable of promoting migration to bone marrow. Blood. 2004;104: 2643-2645.

60. Wang E, Jarrah A, Benard L, et al. Deletion of CXCR4 in cardiomyocytes exacerbates cardiac dysfunction following isoproterenol administration. Gene Ther. 2014;21: 496-506.

61. Albersen M, Berkers J, Dekoninck P, et al. Expression of a distinct set of chemokine receptors in adipose tissue-derived stem cells is responsible for in vitro migration toward chemokines appearing in the major pelvic ganglion following cavernous nerve injury. Sex Med. 2013;1: 3-15.

62. Hoffmann F, Müller W, Schütz D, et al. Rapid uptake and degradation of CXCL12 depend on CXCR7 carboxyl-terminal serine/threonine residues. J Biol Chem. 2012;287: 28362-28377.

63. Lisignoli G, Cristino S, Piacentini A, et al. Hyaluronan-based polymer scaffold modulates the expression of inflammatory and degradative factors in mesenchymal stem cells: Involvement of Cd44 and Cd54. J Cell Physiol. 2006;207: 364-373.

64. Goessler UR, Bugert P, Bieback K, et al. Integrin expression in stem cells from bone marrow and adipose tissue during chondrogenic differentiation. Int J Mol Med. 2008;21: 271-279.

65. Popov C, Radic T, Haasters F, et al. Integrins a $2 \beta 1$ and a $11 \beta 1$ regulate the survival of mesenchymal stem cells on collagen I. Cell Death Dis. 2011;2: e186-e186.

66. Liu H, Xue W, Ge G, et al. Hypoxic preconditioning advances CXCR4 and CXCR7 expression by activating HIF-1a in MSCs. Biochem Biophys Res Commun. 2010;401: 509-515.

67. Liu L, Chen J-X, Zhang X-W, et al. Chemokine receptor 7 overexpression promotes mesenchymal stem cell migration and proliferation via secreting Chemokine ligand 12. Sci Rep. 2018;8: 1-10.

68. Lee YJ, Baek SE, Lee S, et al. Wound-healing effect of adipose stem cell-derived extracellular matrix sheet on full-thickness skin defect rat model: Histological and immunohistochemical study. Int Wound J. 
2019;16: 286-296.

69. Lee KB, Choi J, Cho SB, et al. Topical embryonic stem cells enhance wound healing in diabetic rats. J Orthop Res. 2011;29: 1554-1562.

70. Roy DC, Mooney NA, Raeman CH, et al. Fibronectin matrix mimetics promote full-thickness wound repair in diabetic mice. Tissue Eng Part A. 2013;19: 2517-2526.

71. Hocking DC, Brennan JR and Raeman CH. A Small Chimeric Fibronectin Fragment accelerates dermal Wound repair in diabetic mice. Adv Wound Care. 2016;5: 495-506.

72. Qiu Z, Kwon A-H and Kamiyama Y. Effects of plasma fibronectin on the healing of full-thickness skin wounds in streptozotocin-induced diabetic rats. J Surg Res. 2007;138: 64-70.

73. Damås JK, Wæhre T, Yndestad A, et al. Stromal Cell-Derived Factor-1a in Unstable Angina: Potential Antiinflammatory and Matrix-Stabilizing Effects. Circulation. 2002;106: 36-42.

\section{Figures}



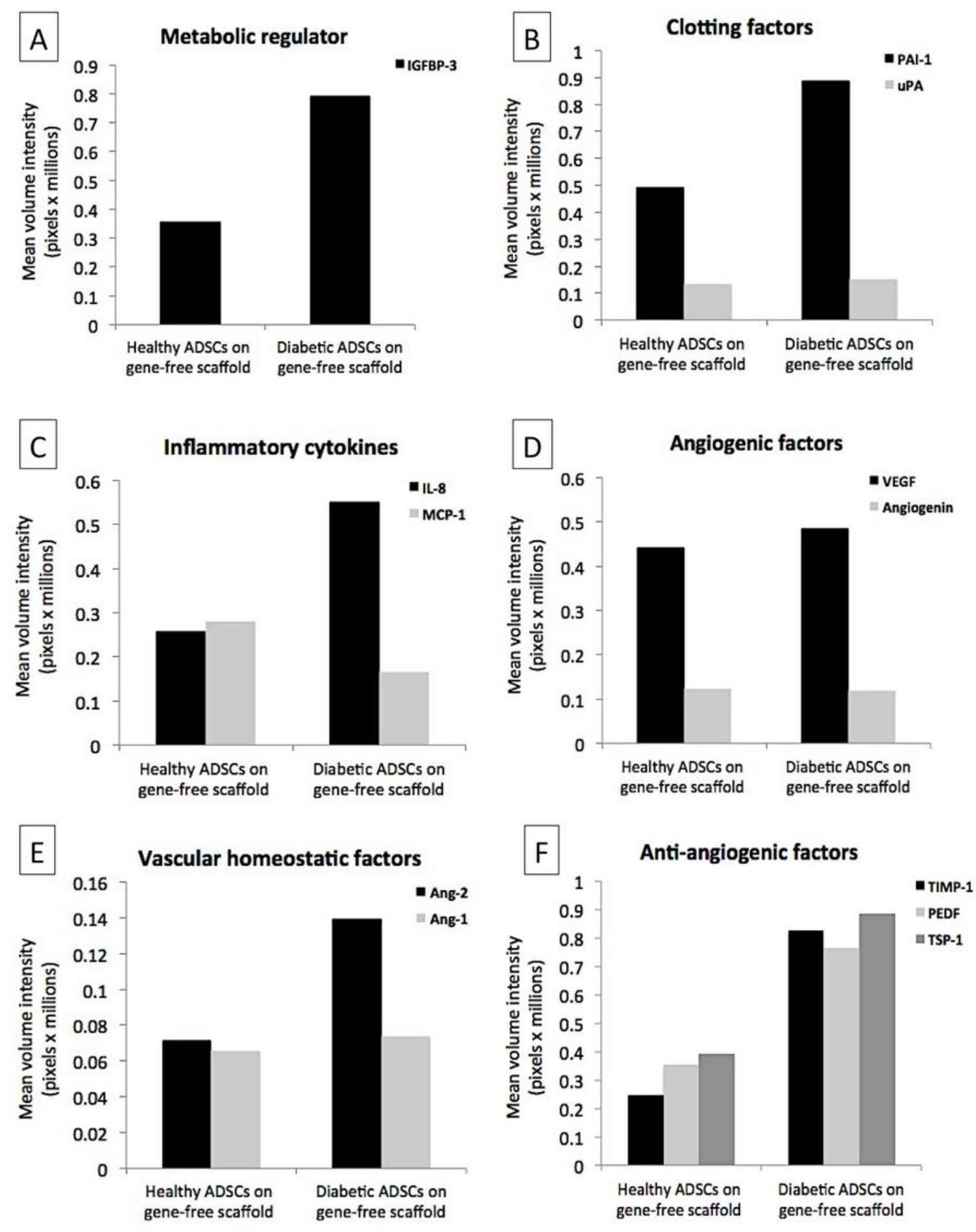

\section{Figure 1}

Functional factors produced by the diabetic ADSCs on the gene-free scaffold compared to healthy ADSCs on the gene-free scaffold on day 7. Overall, the diabetic ADSCs on the gene-free scaffold produced a 2fold elevated production of A) IGFBP-3 B) PAI-1 C) IL-8 E) Ang-2) and F) Anti-angiogenic factors - TIMP-1, PEDF and TSP-1, with respect to healthy ADSCs on the gene-free scaffold. However, no difference could be observed in the production of D) angiogenic factors- VEGF and angiogenin. 

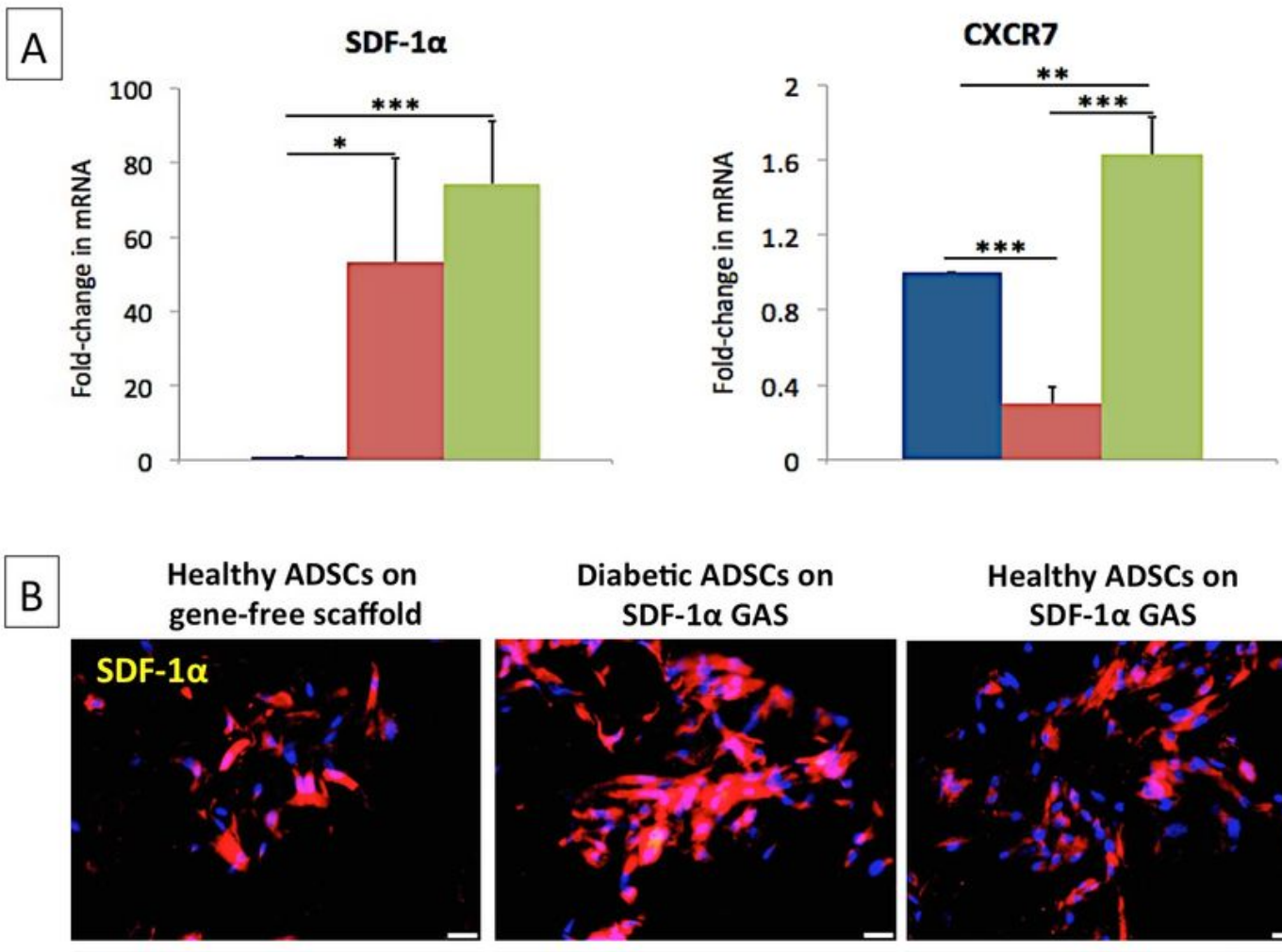

\section{Healthy ADSCs on} SDF-1 $\alpha$ GAS
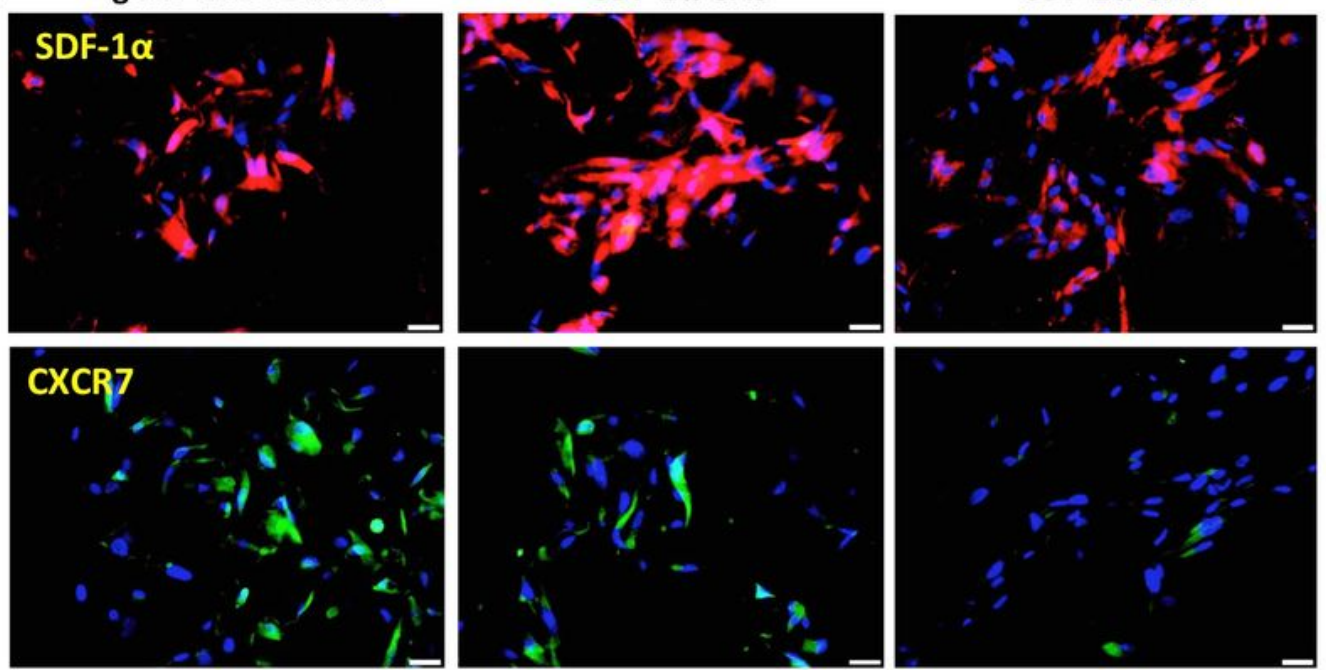

C
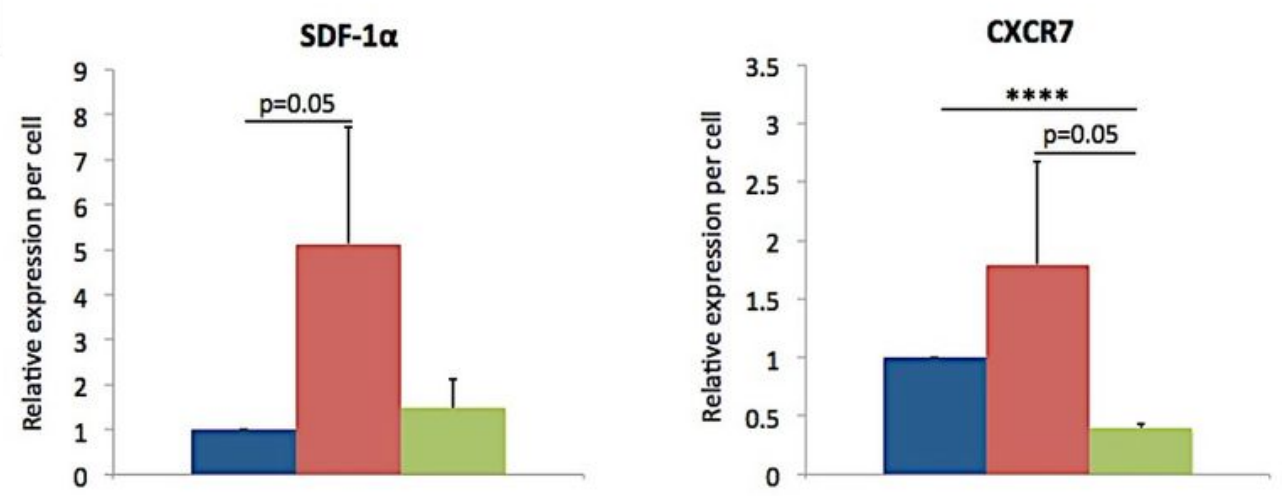

Figure 2

Impact of SDF-1a gene-activated scaffold on the activation of SDF-1a and its downstream signaling mediators in diabetic ADSCs. A) SDF-1a gene-activated scaffold caused the overexpresion of SDF-1a mRNA in both healthy and diabetic ADSCs. The overexpression of SDF-1 a mRNA had a minimal effect on the expression of CXCR7 mRNA in diabetic ADSCs while it increased significantly in healthy ADSCs. B) Immunofluorescence images showing the abundancy of SDF-1a and CXCR7 in the ADSCs groups. C) The 
diabetic ADSCs on the SDF-1a gene-activated scaffold expressed the highest level of SDF-1a and CXCR7 proteins while healthy ADSCs displayed the weakest expression of CXCR7. ${ }^{*}, * \star, * \star \star$ and $* \star \star \star$ indicates statistical significance of $p<0.05, p<0.01, p<0.005$ and $p<0.001$ respectively. Data are presented as mean \pm standard deviation $(n=3)$. Scale bar $20 \mu \mathrm{m}$.
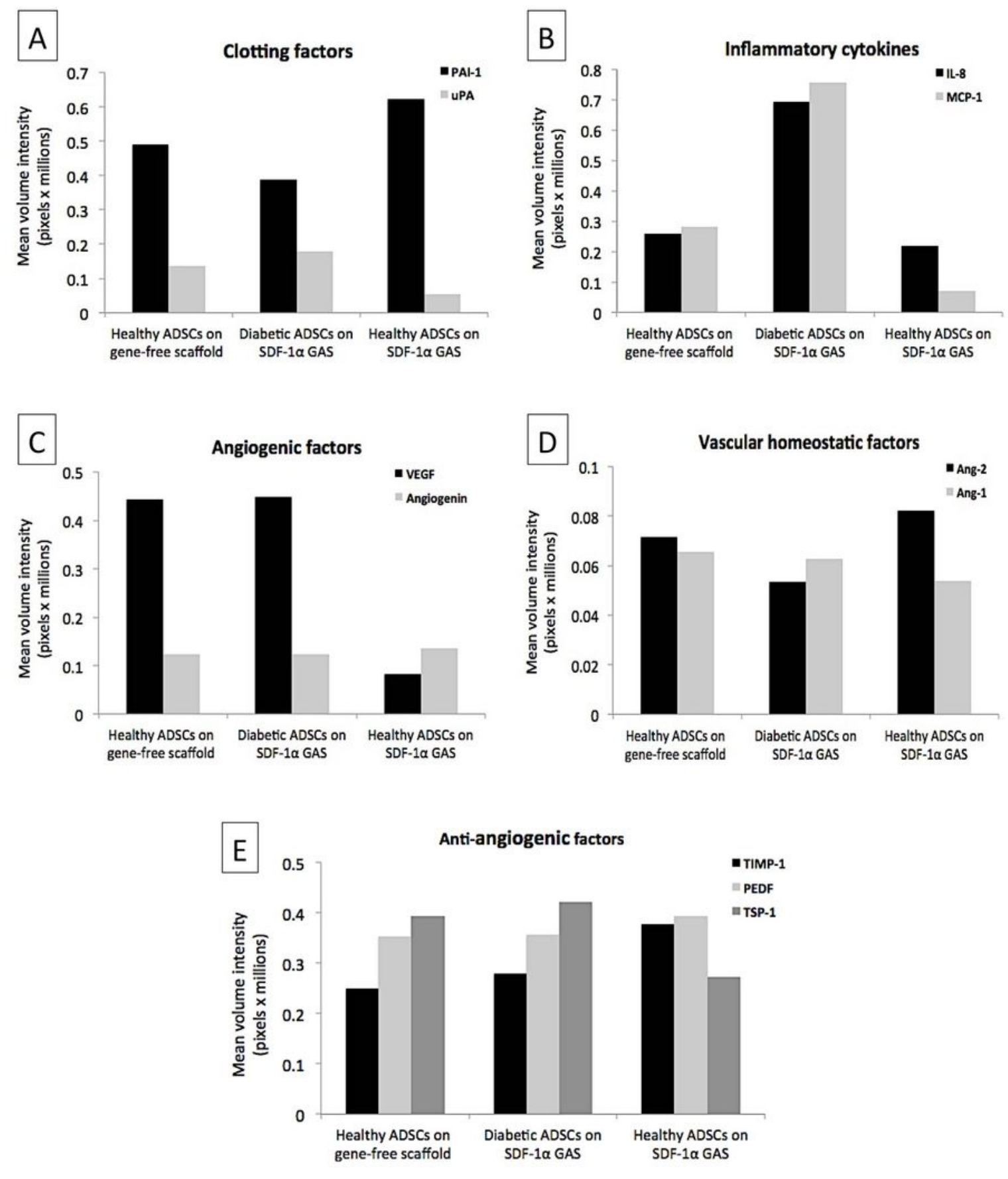

Figure 3 
Impact of SDF-1a gene-activated scaffold on the production of functional factors in healthy and diabetic ADSCs. Transfection of the diabetic ADSCs within the SDF-1a gene-activated scaffold resulted in restoration of a healthy-like signaling of functional factors in the diabetic ADSCs. On the other hand, the SDF-1 a gene-activated scaffold caused a moderate deviation in the signaling pattern of the functional factors in the healthy ADSCs relative to its unactivated equivalent.
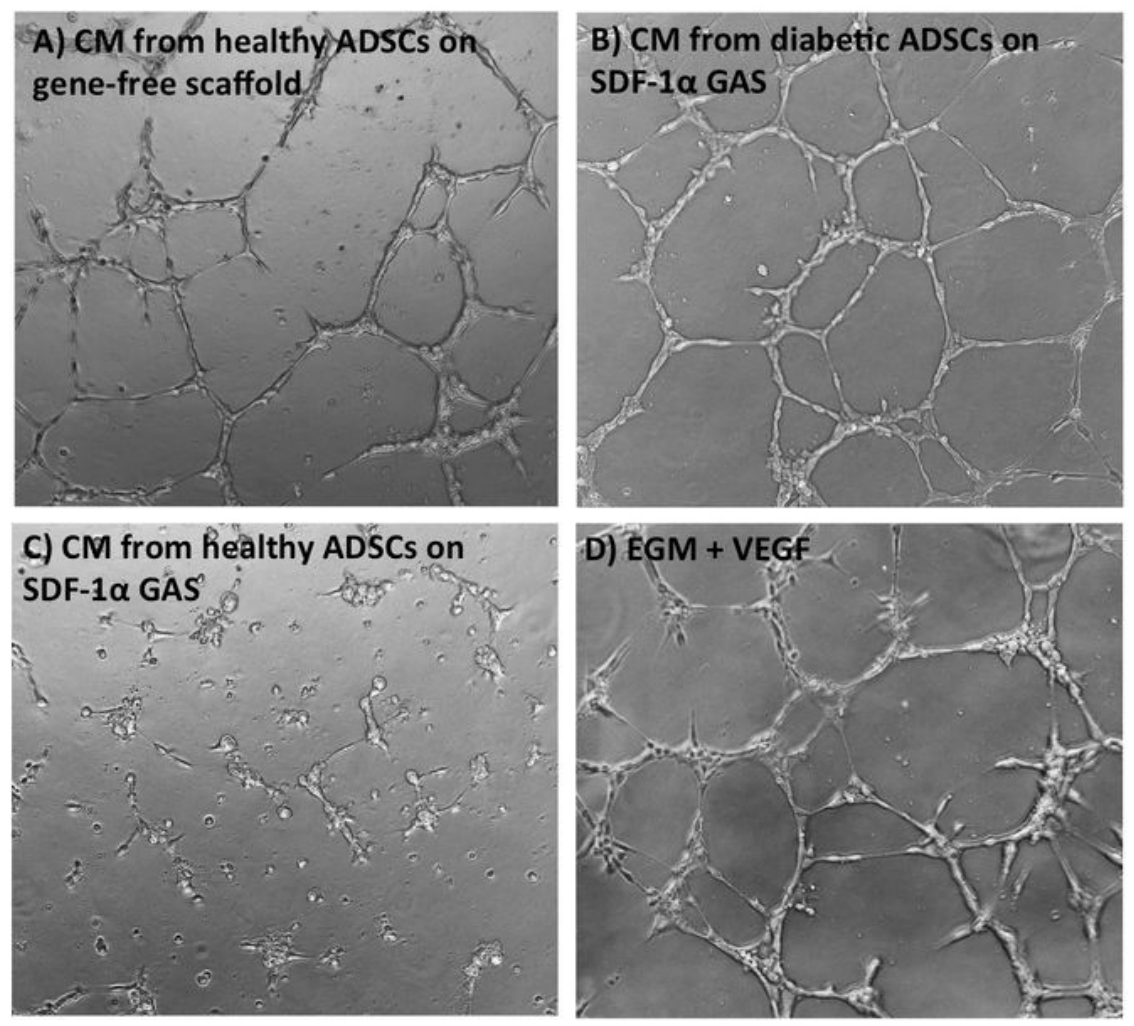

\section{Figure 4}


Pro-angiogenic impact of secreted factors from the transfected healthy and diabetic ADSCs. Overall, diabetic ADSCs on the SDF-1a gene-activated scaffold induced the strongest pro-angiogenic response in human endothelial cells. $8 \mathrm{~h}$ post-exposure, CM from diabetic ADSCs (B) significantly enhanced endothelial netwok branching $(p<0.01)$ as well as tubules formation $(p<0.05)$ compared to that induced by its healthy counterpart (C). EGF + VEGF was used as reference medium to stimulate endothelial angiogenesis (D).

$\square$ Healthy ADSCs on gene-free scaffold $\square$ Diabetic ADSCs on SDF-1 $\alpha$ GAS

A

FN-1

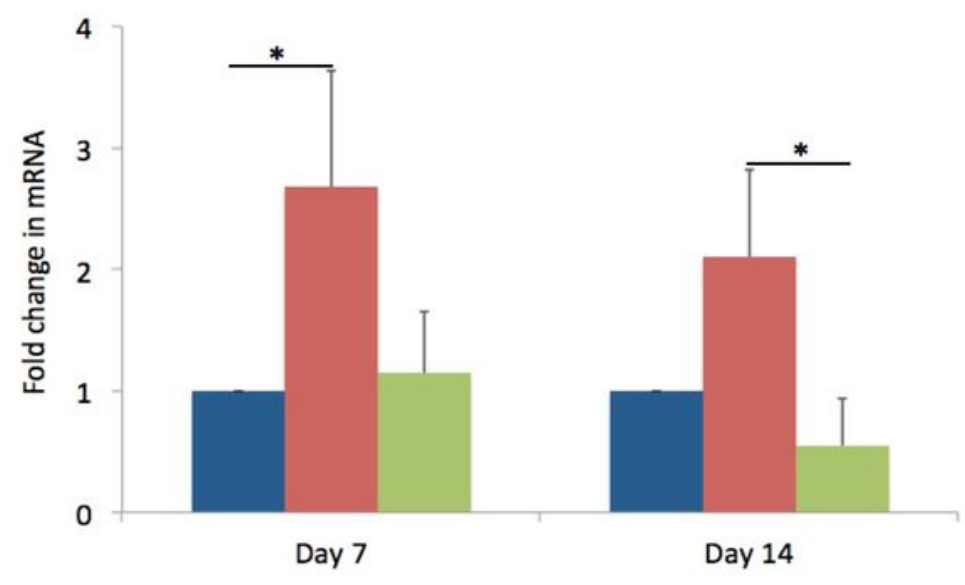

B COL4A1

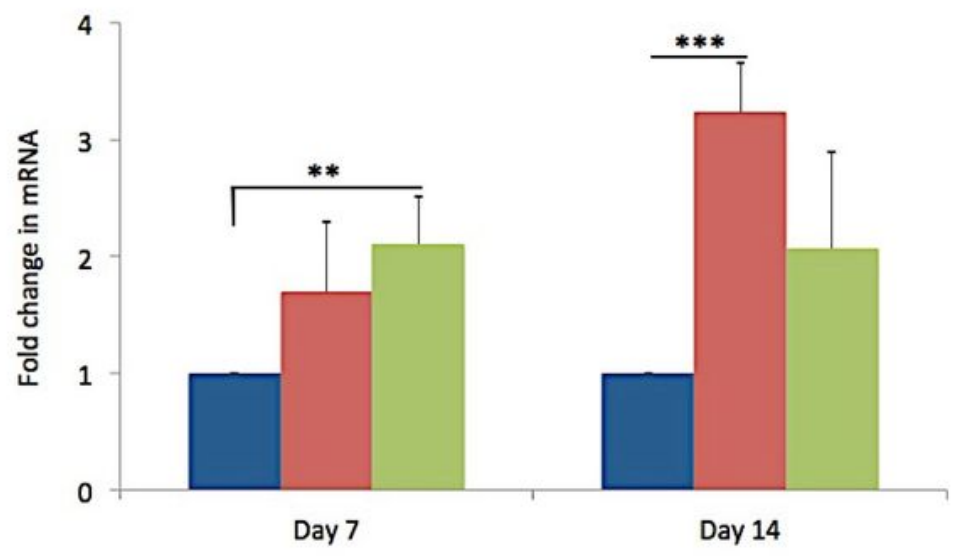


Effect of SDF-1a gene-activated scaffold on the expression of pro-wound healing matrix genes in healthy and diabetic ADSCs. A) On day 7, the transfected diabetic ADSCs on the gene-activated scaffold showed a significantly $(p<0.05)$ enhanced transcription of the FN1 gene than the healthy ADSCs on the gene-free scaffold. B) At the same time point, the healthy ADSCs on the gene-activated scaffold showed a significant activation of the COL4A1 gene than its gene-free equivalent. *, ** and *** indicates statistical significance of $p<0.05, p<0.01$ and $p<0.005$ respectively. Data are presented as mean \pm standard deviation $(n=3)$.

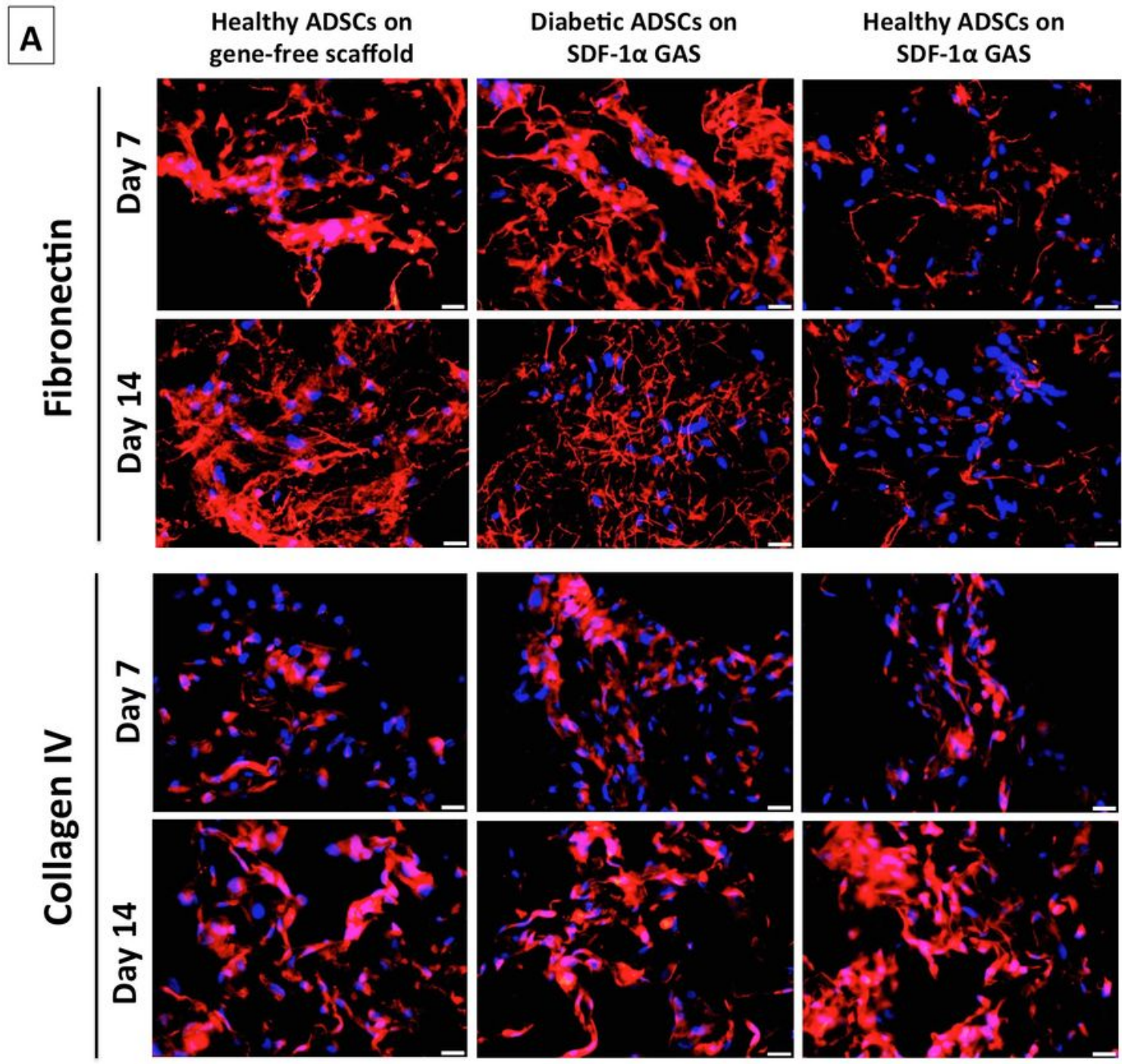

B
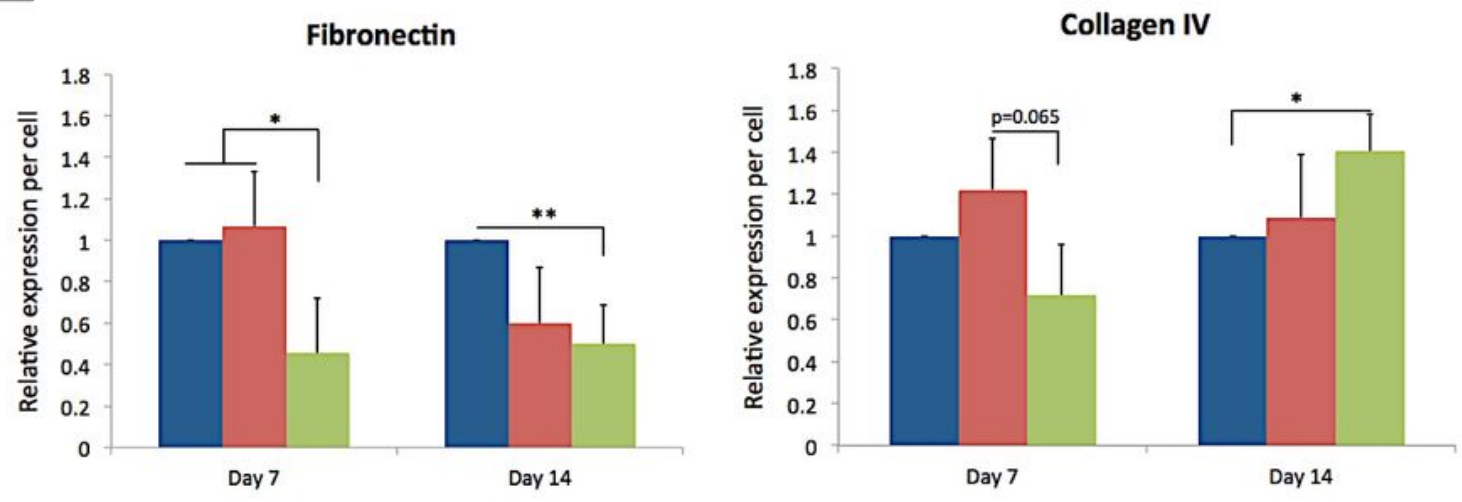


\section{Figure 6}

Effect of SDF-1a gene-activated scaffold on the deposition and remodelling of pro-wound healing matrix proteins in healthy and diabetic ADSCs. A) Relative to the healthy ADSCs on the gene-free scaffold, diabetic ADSCs on the SDF-1a gene-activated scaffold showed a significant decrease in the deposition of fibronectin matrix while increasing the deposition of collagen IV over time. Contrarily, healthy ADSCs on the SDF-1a gene-activated scaffold deposited minimal amounts of fibronectin matrix throughout the culture period but significantly increased the deposition of collgen IV. B) Semi-quantitative interpretation of spatio-temporal expression of the matrix proteins. * and $* *$ indicates statistical significance of $p<0.05$ and $p<0.01$ respectively. Data are presented as mean \pm standard deviation $(n=3)$. Scale bar $20 \mu m$.

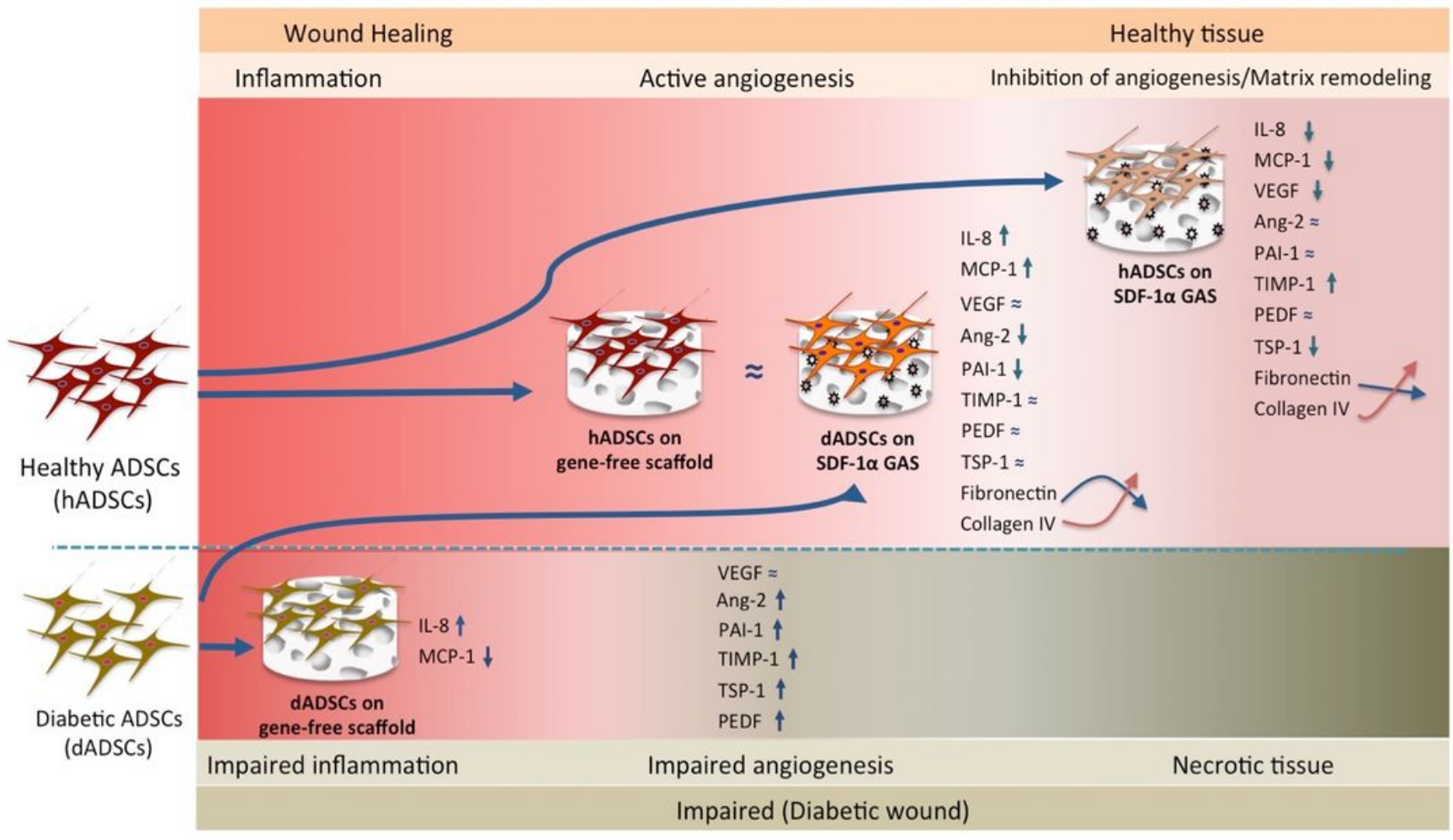

* Arrows indicate change in expression levels relative to healthy ADSCs on the gene-free scaffold

\section{Figure 7}

A schematic of the functional changes induced by SDF-1a gene-activated collagen scaffold in healthy and diabetic ADSCs. 